\title{
An Effective Control Strategy for Pitch control of Wind Energy System Connected with Grid
}

\author{
Devendra Kumar ${ }^{1}$,Dr. Abhishek Verma ${ }^{2}$, Dr. Anup Mishra ${ }^{3}$, Ritu Gautam ${ }^{4}$, Dr. Ashish Kumar \\ Tamrakar ${ }^{5}$ \\ PG Student, Dept. of EEE, Bhilai Institute of technology, Durg, Chhattisgarh, India ${ }^{1}$ \\ Associate professor, Dept. of EEE, Bhilai Institute of technology, Durg, Chhattisgarh, India ${ }^{2}$ \\ Head Of department, Dept. of EEE, Bhilai Institute of technology, Durg, Chhattisgarh, India ${ }^{3}$ \\ Assistant professor, Dept. of EEE, Bhilai Institute of technology, Durg, Chhattisgarh, India ${ }^{4}$ \\ Assistant professor, Dept of CS, RCST,Durg Chhattisgarh, India ${ }^{5}$ \\ mahantidevendramahanti@gmail.com ${ }^{1}$, abhishek.verma@bitdurg.ac.in², \\ anupmishra.bit123@gmail.com ${ }^{3}$, ritu.tripathi7314@gmail.com ${ }^{4}$, ashish.tamrakar1987@gmail.com ${ }^{5}$,
}

\begin{abstract}
Recently the main concern all over the world is carbon emission reduction and due to this renewable energy sources are the main point of attraction for the power generation. Especially wind energy into the electrical power grid is extensively increased, the influence of the wind turbine system on the voltage stability and frequency becomes more and more significant. Wind turbine rotor has different types of loads and these loads results in fatigue and vibration in blades. These loads and losses can overcome by using a good pitch controller. As we know that energy extracted is limited according to Betz law but with the help of good pitch angle controllers it is possible to get desired output in certain conditions. A maximum performance can be obtain by designing a good pitch angle controller. A system with wind turbine generator system connected with grid is designed and simulated in Matlab software with the PID control system and the results are evaluated and by analysing these results some future analysis can be planned.
\end{abstract}

KEYWORDS: PMSG (permanent magnet synchronous generator), WECS (Wind energy conversion system) IGBT (Insulated gate bipolar transistor), THD (Total harmonic distortion), STATCOM (static synchronous compensator), SVC (static VAR compensator).

\section{INTRODUCTION}

In today's era the major problem the world is facing is a lot of carbon emission due to lots of pollution sources but the major source of pollution is the power generation from fossil fuels and that sources are also in a limited stock all over the world. As many countries are in developing stage that's why a lot of construction especially commercial, residential as well as industrial buildings have to be constructed and so the power consumption will increase by 40 to 50 percent in the next upcoming 20 years and the fuels used in all these generations mostly affect the environment badly. To overcome all these situation ministry of new and renewable energy (MNRE) proposed many incentive programs to promote renewable source of energy for generation of electricity like solar energy and wind energy etc. Many research and developments are going on these field right now to improve the system and to get as much energy as we can with the least cost of installation.

In wind energy application variable speed wind turbines have much better performance due to its maximum power point tracking system (MPPT) Now a days doubly fed induction generator are widely used in a variable speed wind turbine but the main drawback is the requirement of gear box to match turbine and rotor speed. The gear box Many times suffers and requires regular maintenance making the system unreliable. [1].

In wind energy system variable speed wind turbine has much better performance due to its maximum power point tracking algorithm. The double fed induction generator which is widely used now a days in variable speed wind turbine has the main drawback of regular maintenance of gear box that makes system unreliable. The reliability of variable speed wind turbine can be improved by using direct drive permanent magnet synchronous generator.

To extract maximum power from the fluctuating wind requires a sophisticated control strategy for the generator. Some control strategies reduce the reliability of the system. For maximum output from PMSG based wind turbine a control strategy has been developed. This design requires IGBT insulated gate bipolar transistor, which is used to control generator torque so as to extract maximum power from the wind. 


\section{MODELLING OF WIND ENERGY CONVERSION SYSTEM}

\section{Wind Turbine}

According to aerodynamics the aerodynamic power of wind turbine can be expressed as

$\operatorname{Pr}=\frac{1}{2} \rho \pi R^{2} \lambda C_{p} V^{3}$

When the rotor speed is adjusted to maintain its optimal value, the maximum power can be gained as

$\operatorname{Prmax}=K_{o p t} \omega^{3}$

Where $\mathrm{K}$ opt is decided by

$K_{o p t}=\rho \pi R^{5} C_{p m a x} \lambda^{3} o p t \ldots(3)$

$T_{\text {mopt }}=K_{\text {opt }}\left(\omega_{\text {mopt }}\right)^{2}$.

The optimum power curve shown by the wind turbine characteristics from where we can get the maximum output power at various wind speed that varies according to wind speed. The optimum power curve shown by the wind turbine characteristics from where we can get the maximum output power at various wind speed that varies according to wind speed. [2]

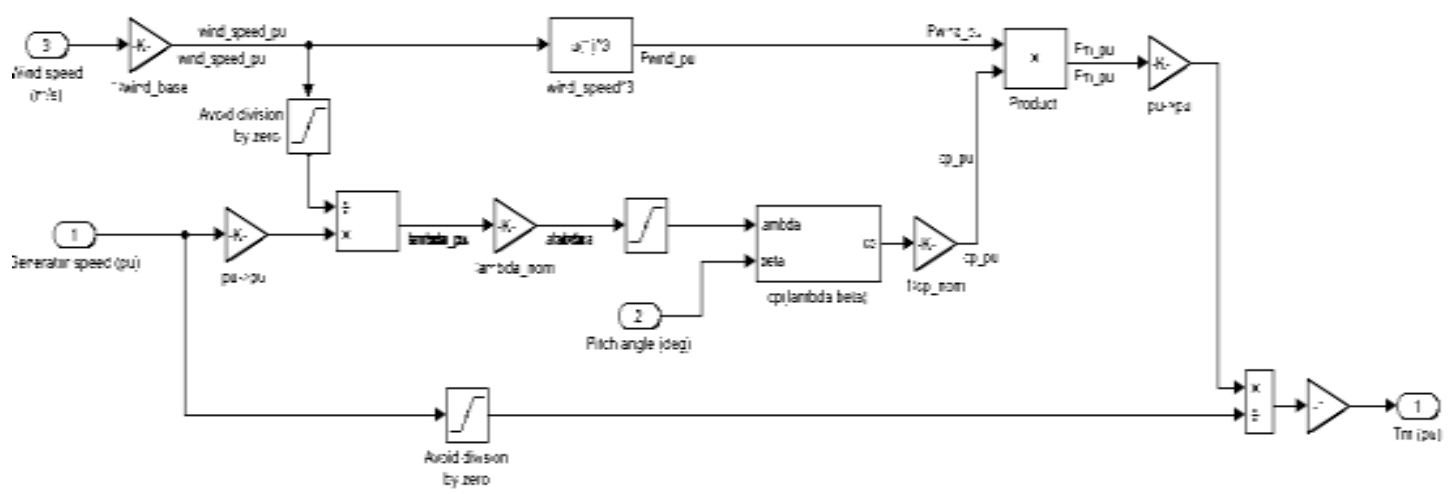

Fig. 1 modelling of wind turbine

\section{Two Mass Drive Train}

Here two mass drive train model used by wind energy conversion system is shown below in fig 1 
Turbine

\section{Shaft}

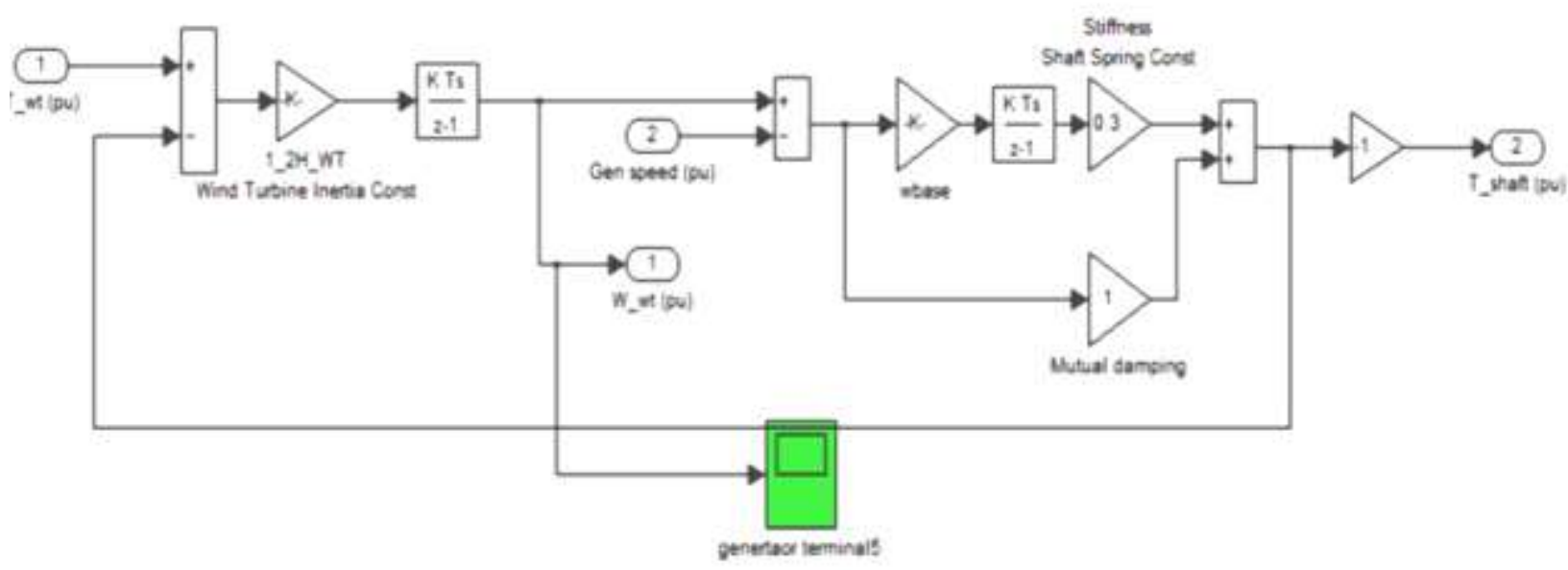

Fig. 2 Two mass drive train

The differential equation governing its mechanical dynamics are as follows [3]

$2 H_{t} \frac{d w t}{d t}=T_{m}-T_{s h}$

$\frac{1}{w e l b} * \frac{d \theta \mathrm{tw}}{d t} w_{t}-w_{r}$

$2 \frac{H_{g w r}}{d t}=T_{s h}-T_{g}$

Where $\mathrm{H}_{\mathrm{t}}$ is the inertia constant of the turbine, $\mathrm{H}_{\mathrm{g}}$ is the inertia Constant of the PMSG, $\theta \mathrm{tw}$ is the shaft twist angle, $\mathrm{wt}_{\mathrm{t}}$ is the Angular speed of the wind turbine in p.u., wr is the rotor speed of the PMSG in p.u., Welb is the electrical base speed, and the Shaft torque Tsh is

$T_{s h}=K_{s h} \theta_{t w}+\frac{D_{t} \theta t_{w}}{d t}{ }_{0}$ Where $K_{s h}$ is the shaft stiffness and $D_{t}$ is the damping coefficient.

\section{Synchronous generator}

The permanent magnet synchronous machine operates as a generator .The electrical and mechanical parts of this machine is represented by second order state space model. The sinusoidal model assumes that the flux established by the permanent magnet is sinusoidal which implies that electromotive forces are sinusoidal. These equations are represented in rotor reference frame .All quantities in the rotor reference frame referred to the stator. [4]

$$
\begin{gathered}
\frac{d}{d t} i_{d}=\frac{1}{L_{d}}-\frac{R}{L_{d}} i_{d}+\frac{L_{q}}{L_{d}} P_{w r} i_{d}-\lambda_{p w r} i_{d}-\frac{\lambda_{p w r}}{L_{q}} \\
T_{e}=1.5 p\left[\lambda_{i q}+\left(L_{d}-L_{q}\right) i_{d} i_{q}\right] \ldots \ldots \ldots \ldots \ldots \\
L_{a b}=L_{d}+L_{q}+\left(L_{q}-L_{d}\right) \cos \left(2 \theta_{e}+\frac{\pi}{3}\right) \ldots
\end{gathered}
$$

$\theta_{e}$ Represents the electrical angle

$\mathrm{Lq}, \mathrm{Ld} \mathrm{q}$ and $\mathrm{d}$ axis inductances

Lq, Ld q and d axis inductances

$\mathrm{R}$ Resistance of the stator windings

Iq, Id $q$ and $d$ axis currents

$\mathrm{Vq}$, Vd q and $\mathrm{d}$ axis voltages

Wr Angular velocity of the rotor

$\lambda$ Amplitude of the flux induced by the permanent magnets of the rotor in the stator phases

P Number of pole pairs

Te Electromagnetic torque

\section{Control System of Inverter}

In this wind energy conversion system the output voltage is controlled through amplitude and frequency. Power from wind 
turbines fed to converters to maintain the output voltage at certain values. The active and reactive power exchange are a function of amplitude and frequency at terminals of grid side converters.

Phase voltages are converted to rms values and then compare it with reference values and supplying this rms value to PI controller. A particular value of voltage is given to reference voltage of PWM. This may be have a fixed reference value or calculate by peak detection method. The fig of control system shown below:

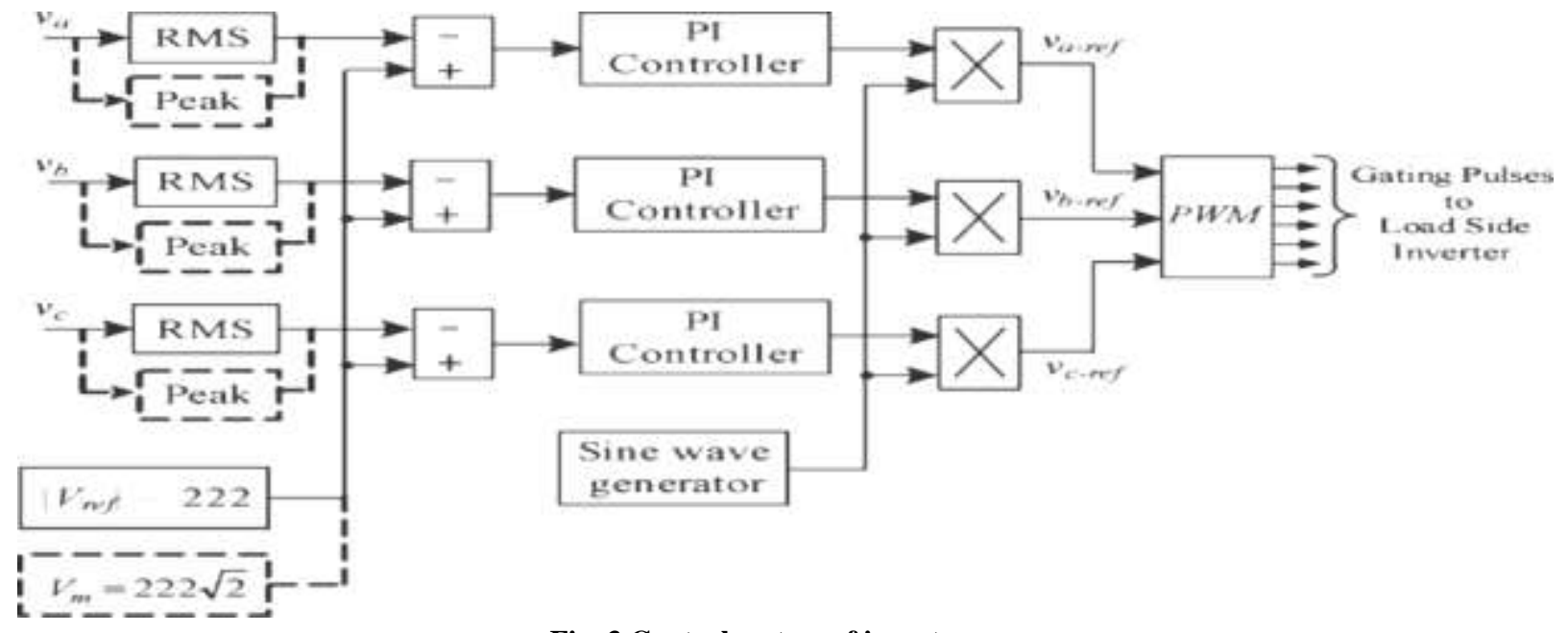

Fig. 3 Control system of inverter

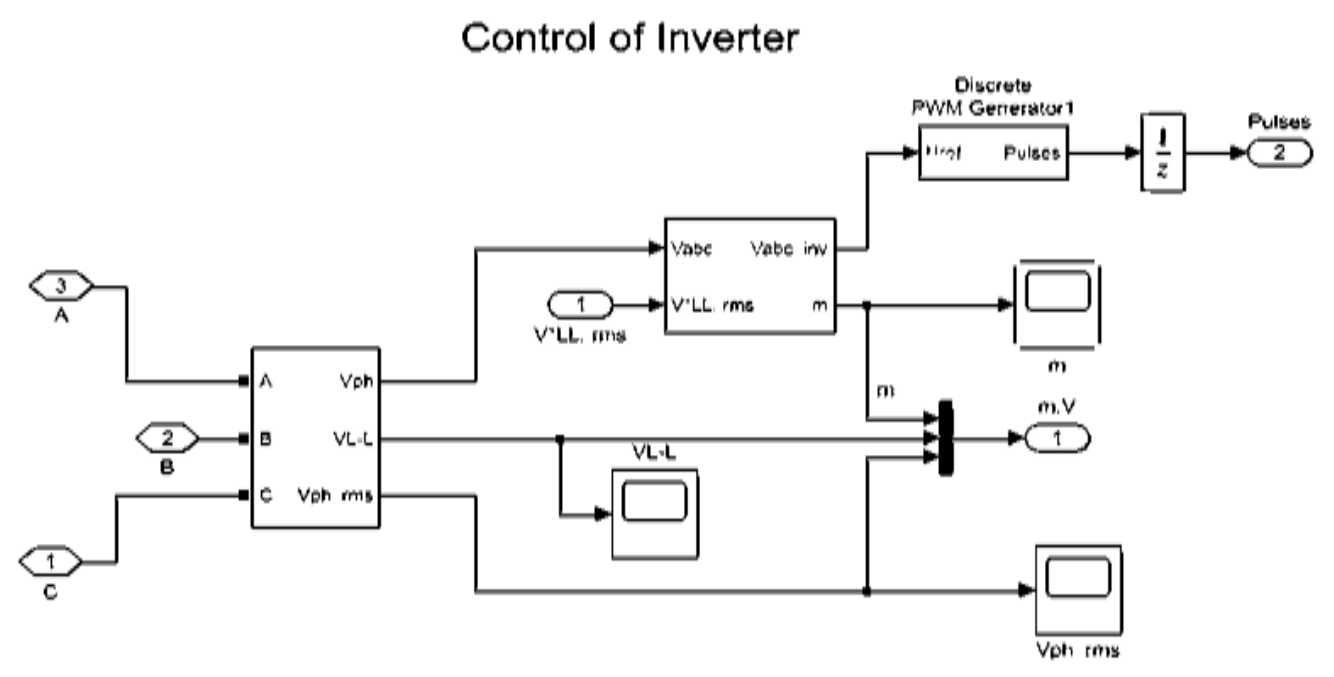

\section{Pitch Control System}

Fig. 4 Overall Control system of inverter

The rotor speed of wind turbine can be controlled by PID controller, Such PID controller is given in figure 5. Where, $\Delta \omega \mathrm{t}(s)$ : is the variance between actual rotor speed and reference rotor speed.

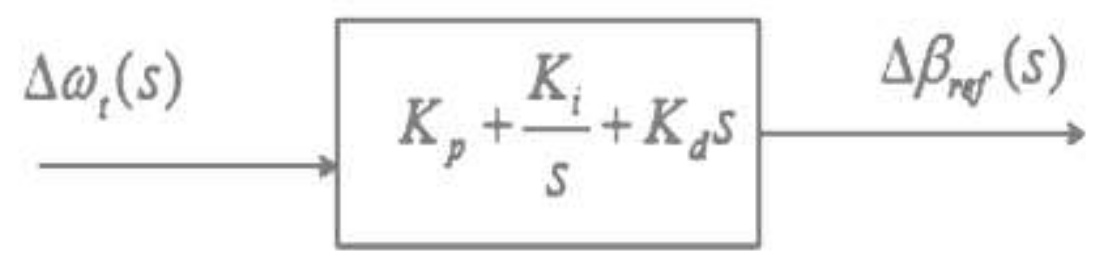

Fig. 5 PID controller 


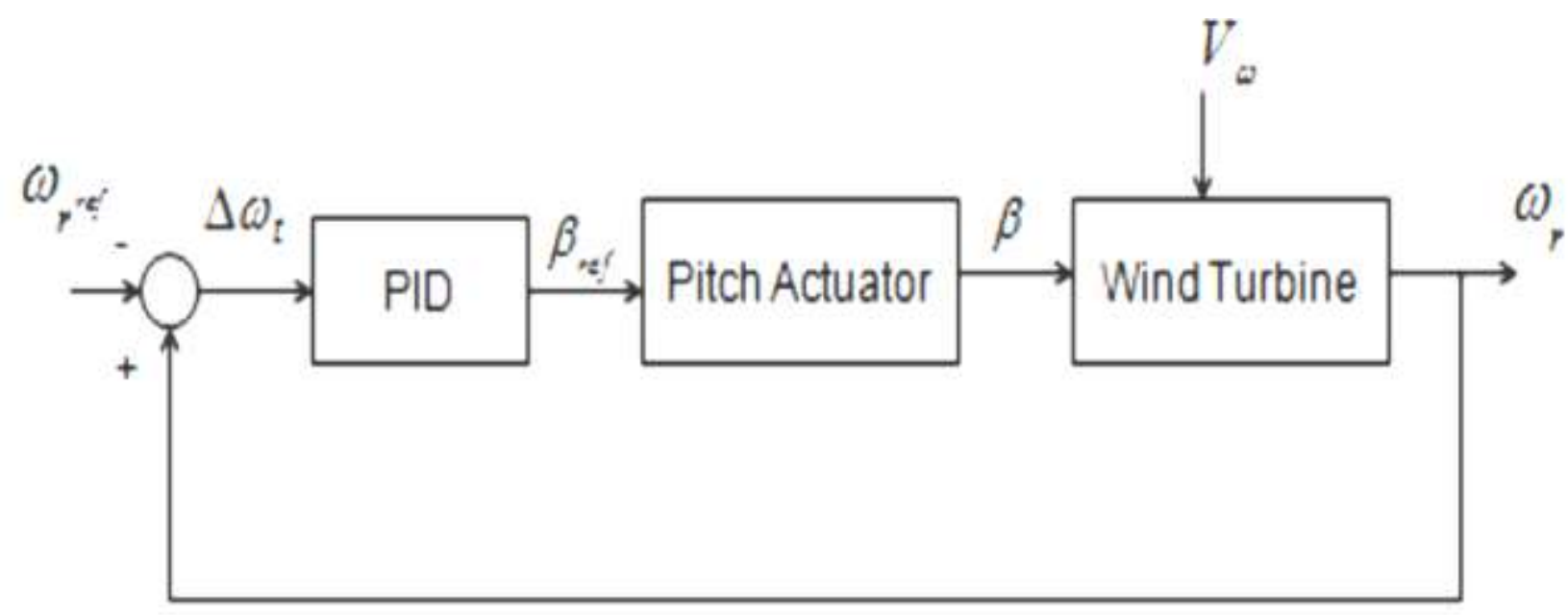

Fig. 6 Block diagram of control system

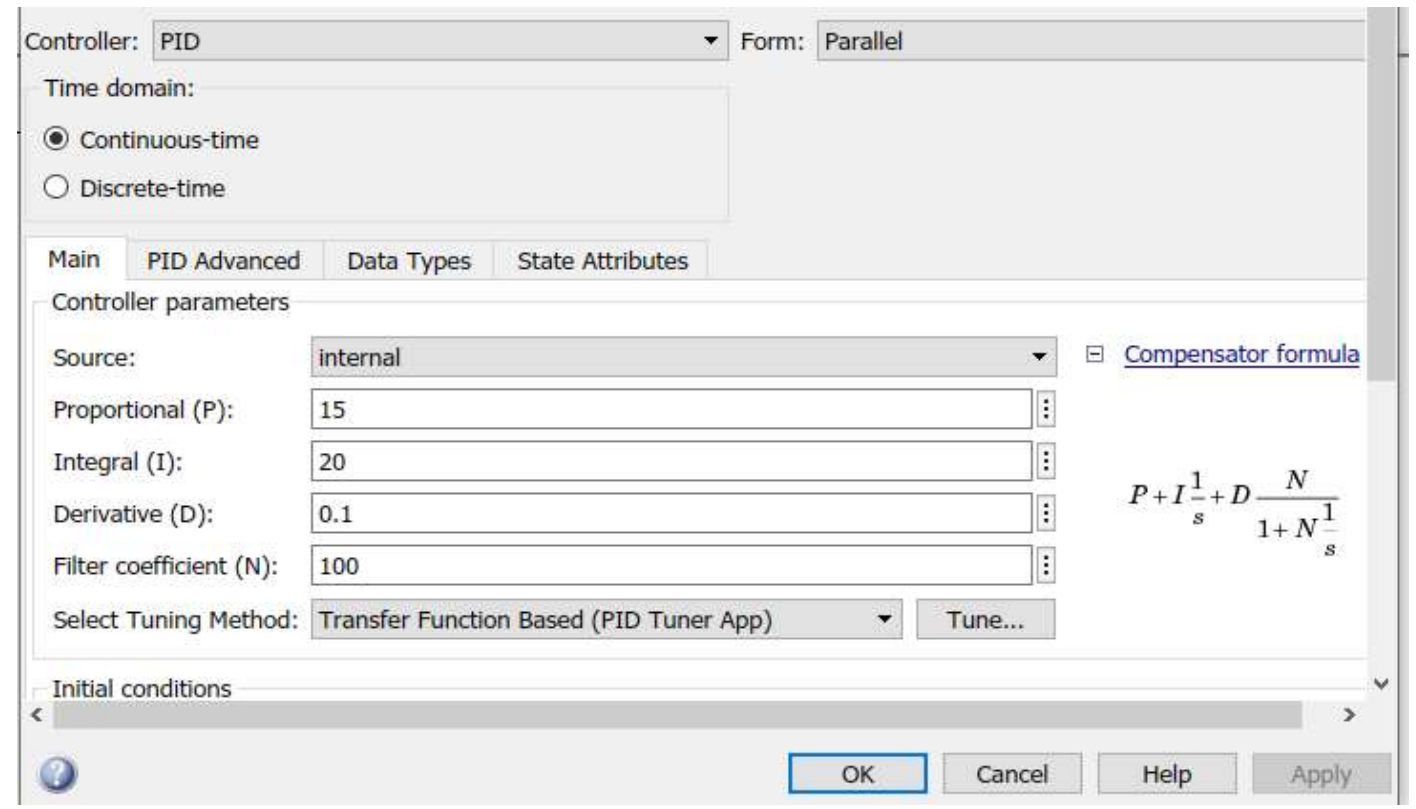

Fig. 7 PID control Parameters

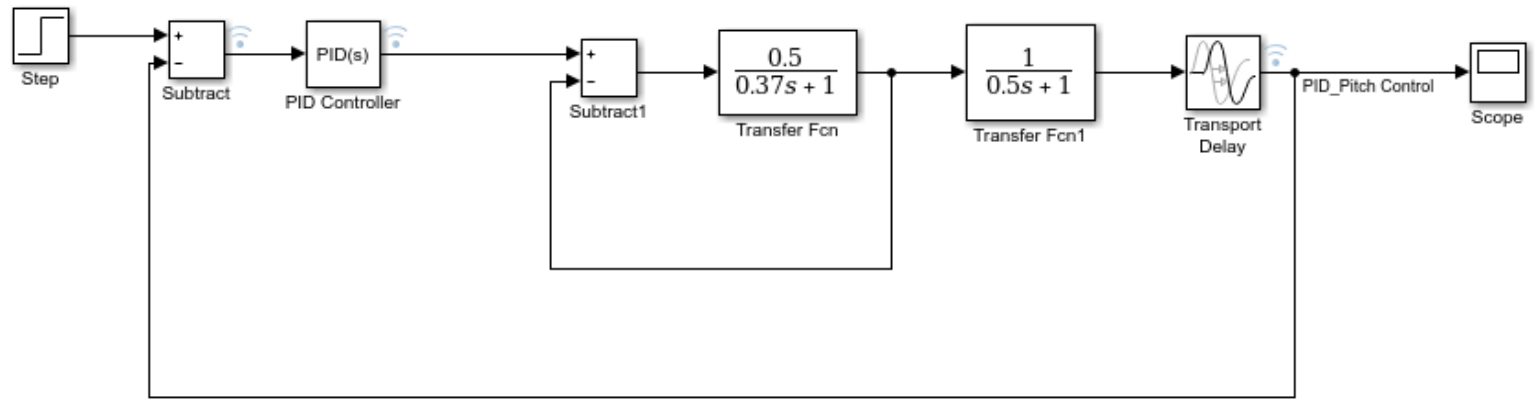

Fig. 8 Simulink diagram of PID control Parameters

The Simulink model of wind turbine pitch control system with conventional PID Controller is shown in Fig. 8 


\section{SYSTEM MODEL}

踏

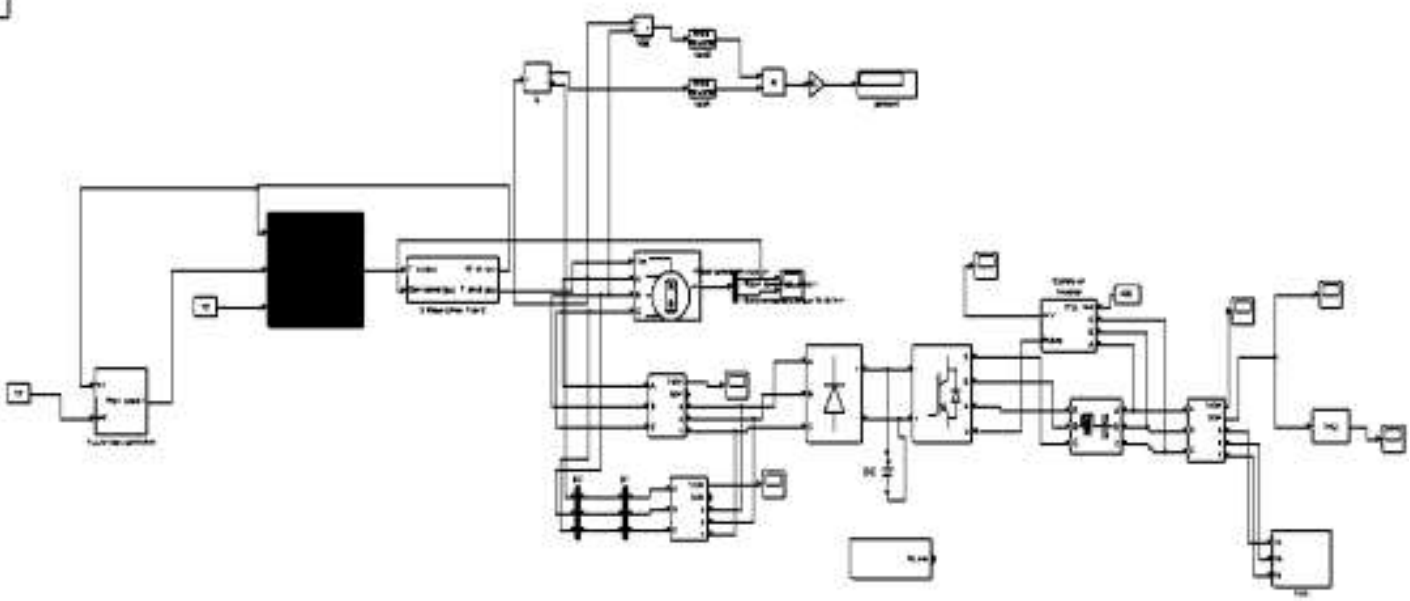

Fig. 8 Overall model of wind energy conversion system

Table-1: Parameters of turbine generator system

\begin{tabular}{|c|c|}
\hline Wind Turbine Parameters & Values \\
\hline Density of air & $1.225 \mathrm{~kg} / \mathrm{m}^{2}$ \\
\hline Area swept by blades & $1.06 \mathrm{~m}^{2}$ \\
\hline Base wind speed & $12 \mathrm{~m} / \mathrm{s}$ \\
\hline
\end{tabular}

Table-2: Permanent magnet synchronous generator

\begin{tabular}{|c|c|}
\hline PMSG & Values \\
\hline No of poles & 10 \\
\hline Rated speed & $153 \mathrm{rad} / \mathrm{s}$ \\
\hline Rated current & 12 amp \\
\hline Armature resistance & $\mathbf{0 . 4 2 5 \Omega}$ \\
\hline Magnetic flux linkage & $\mathbf{0 . 4 3 3}$ wb \\
\hline
\end{tabular}




\section{RESULT AND DISCUSSION}

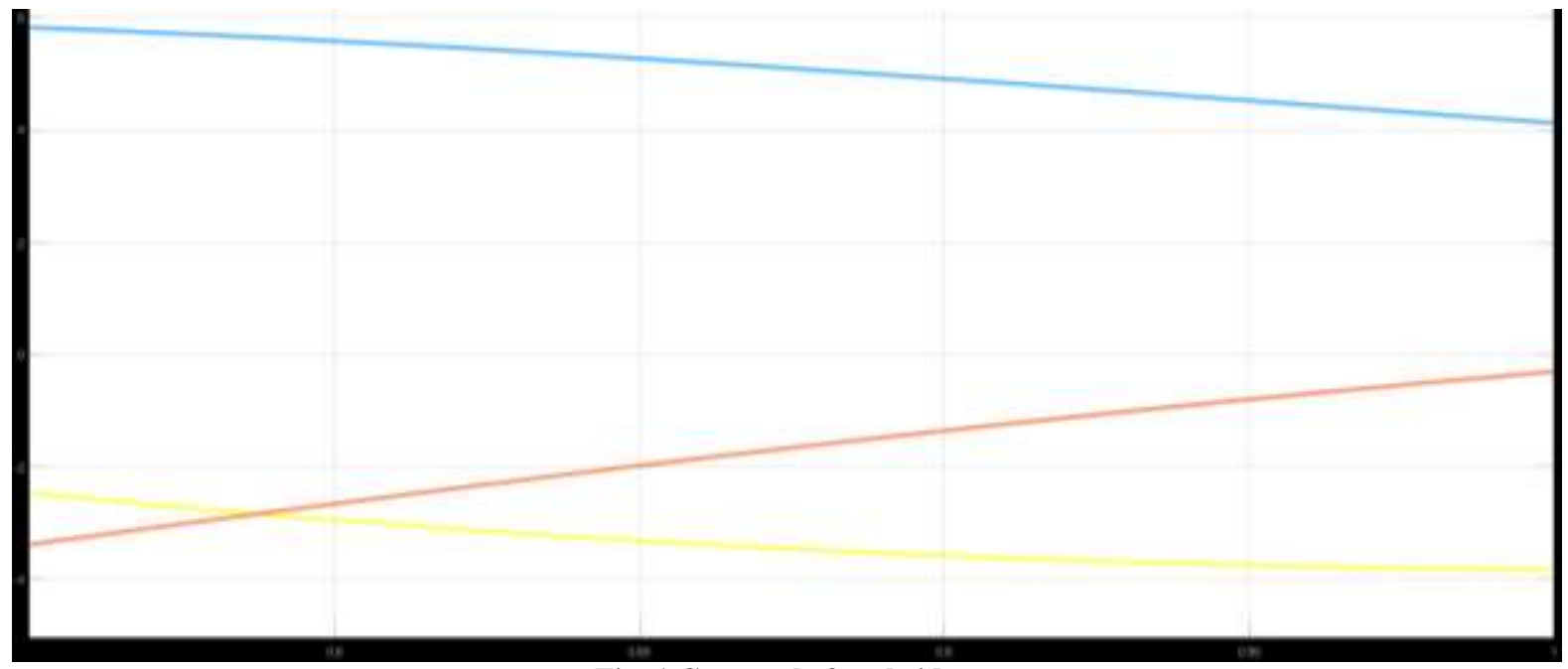

Fig. 1 Current before bridge

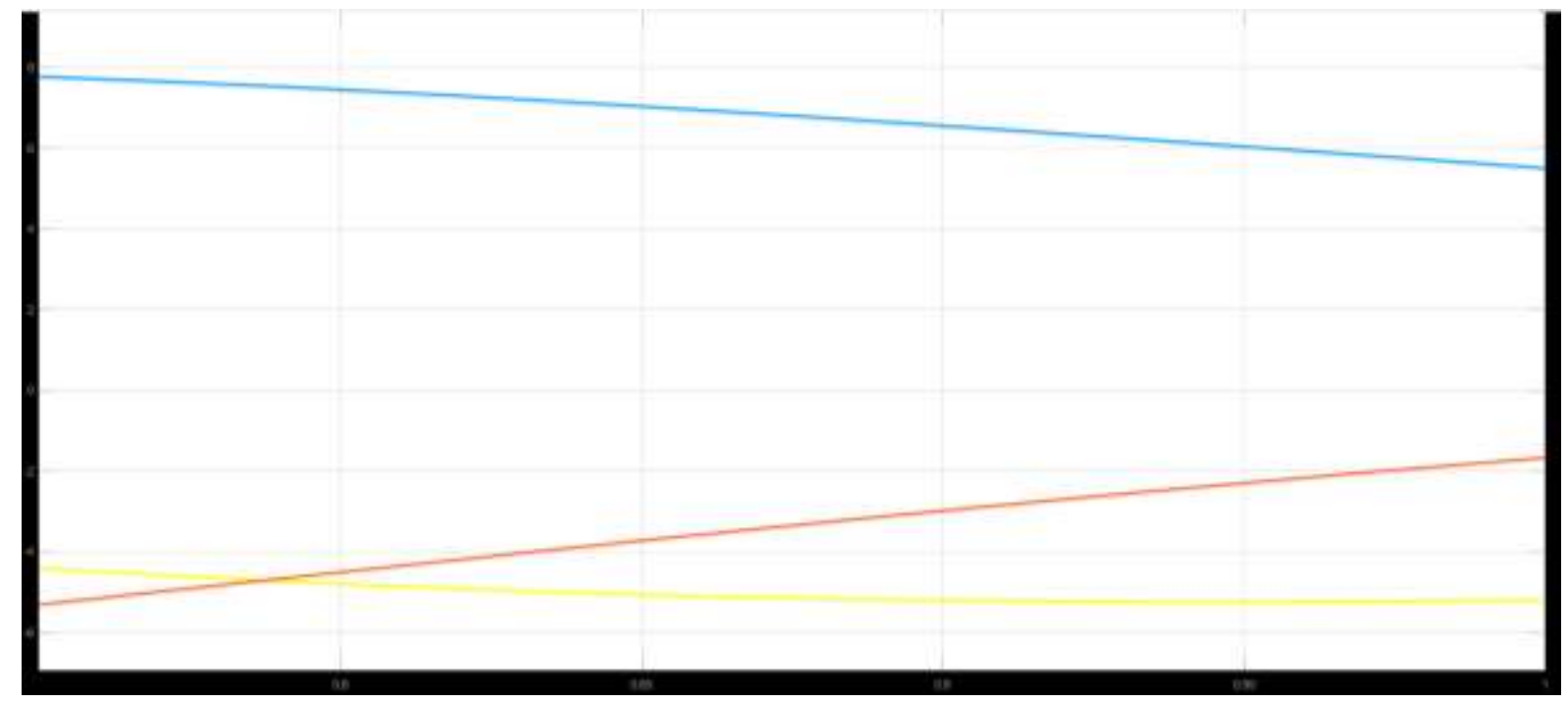

Fig. 2 Voltage before bridge 


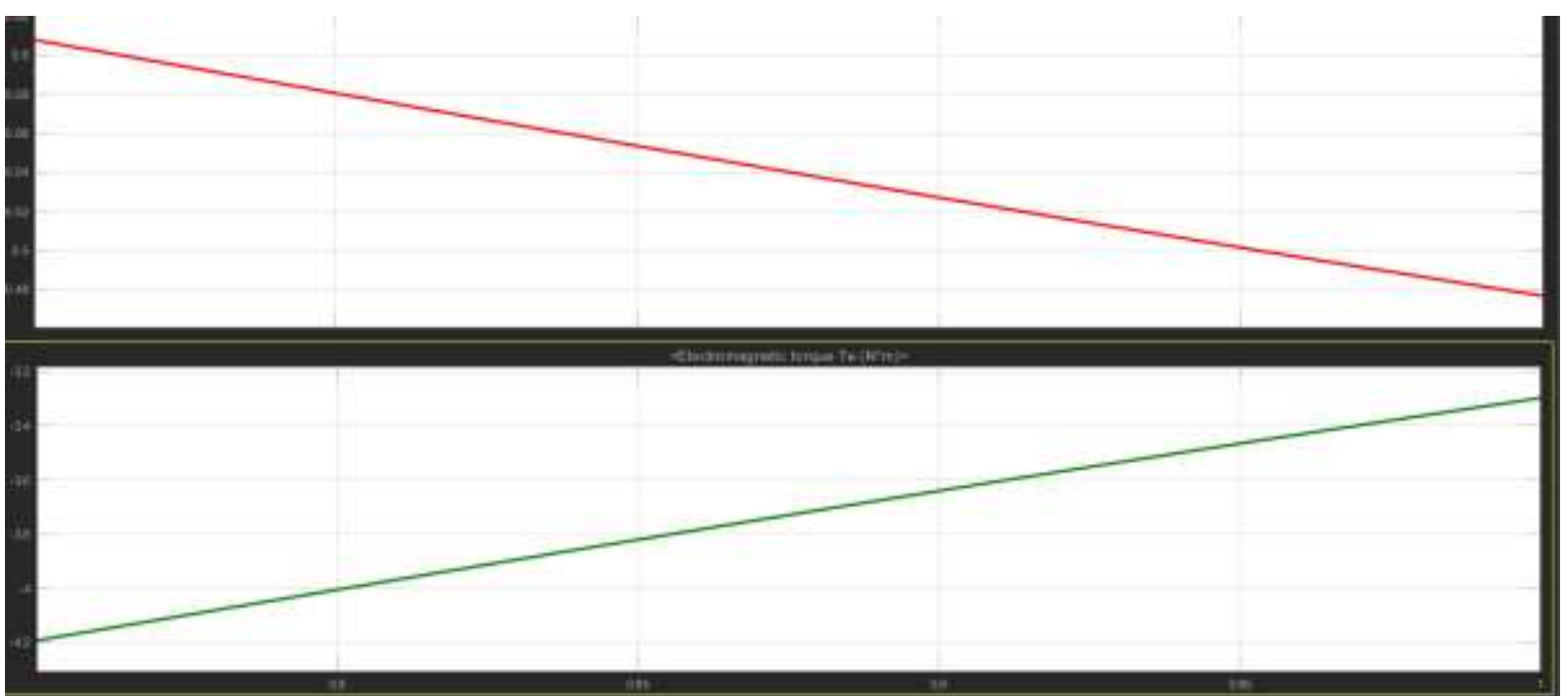

Fig .3 Rotor speed and electromagnetic torque

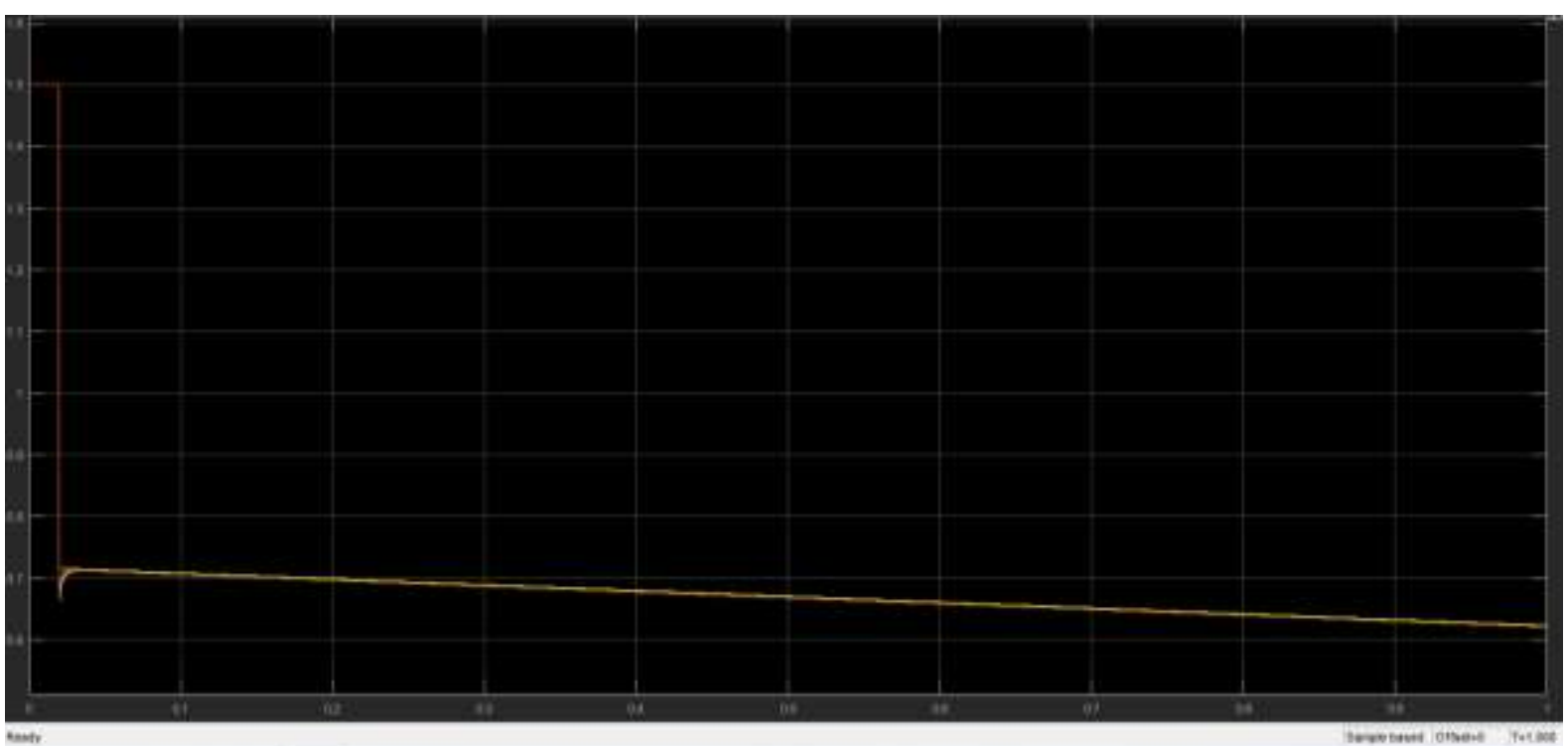

Fig .4 Modulation index

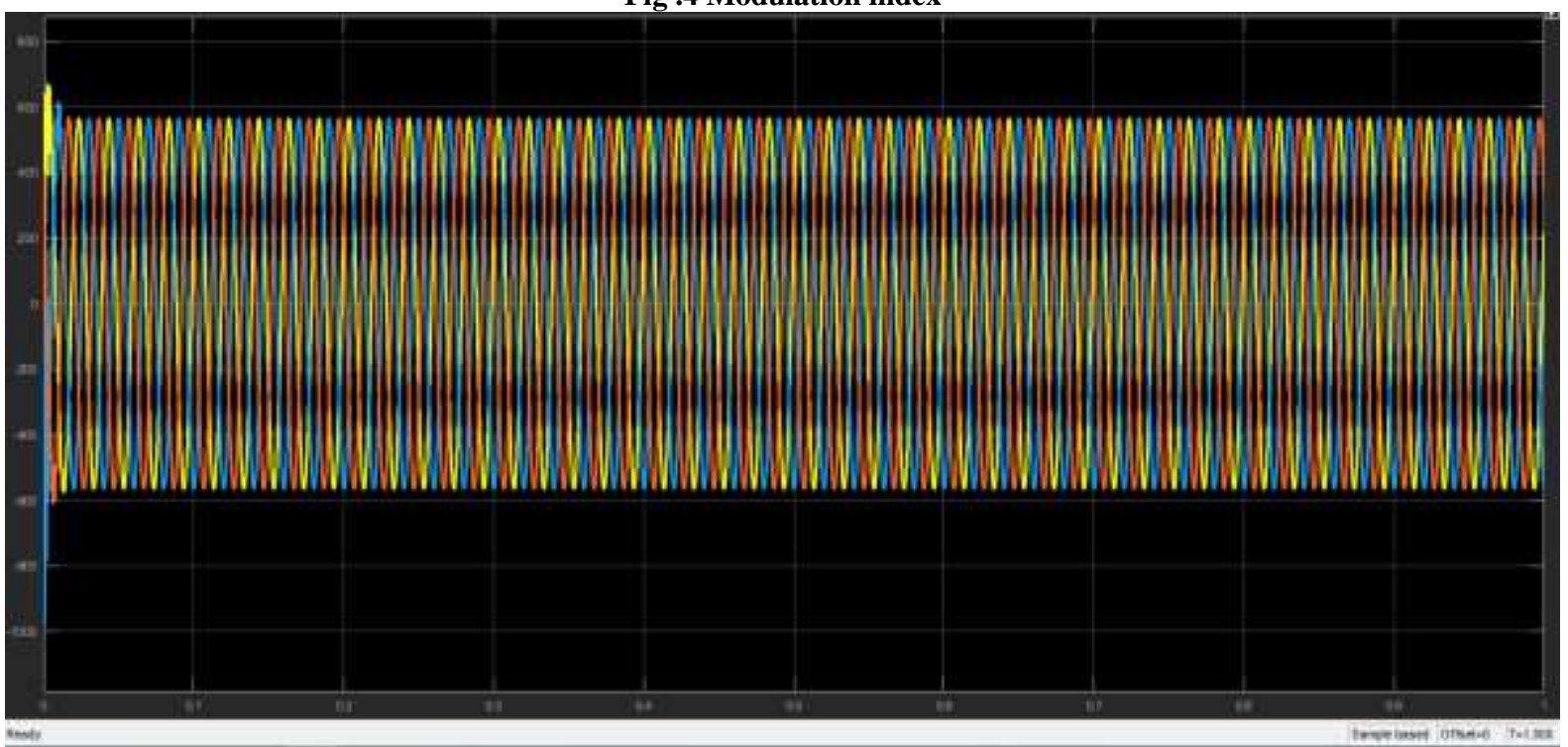

Fig .4 Line to line voltage before filter 


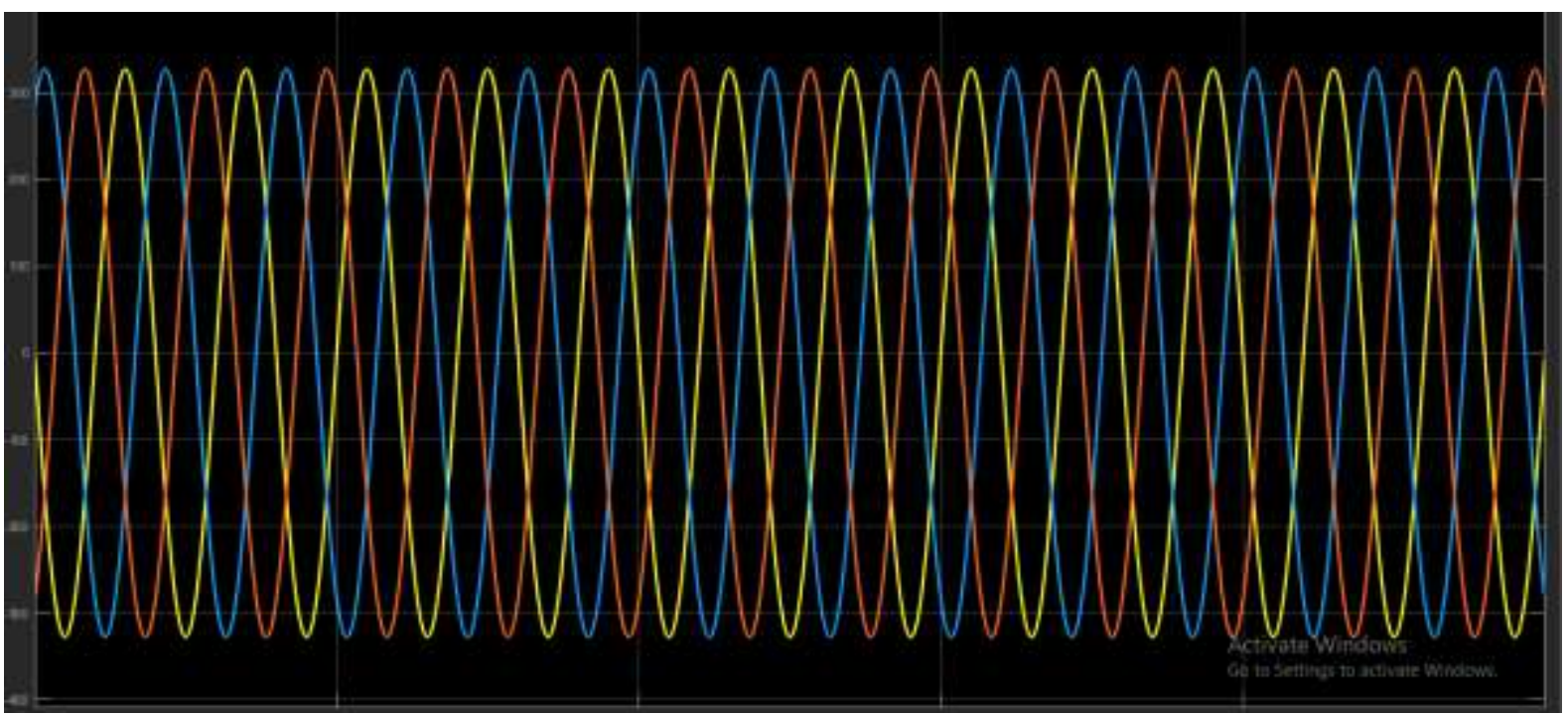

Fig .5 Voltage after filter

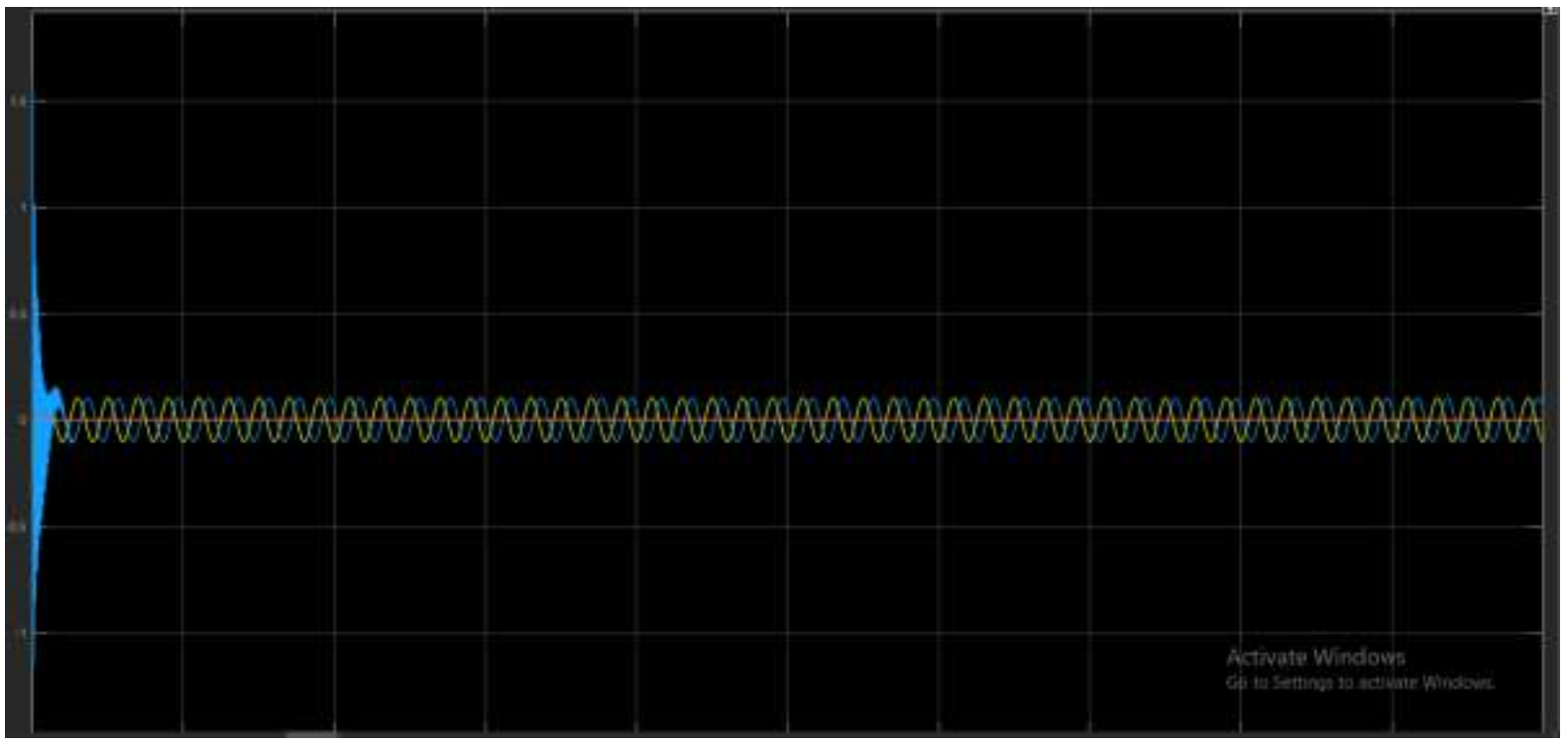

Fig .6 Current after filter

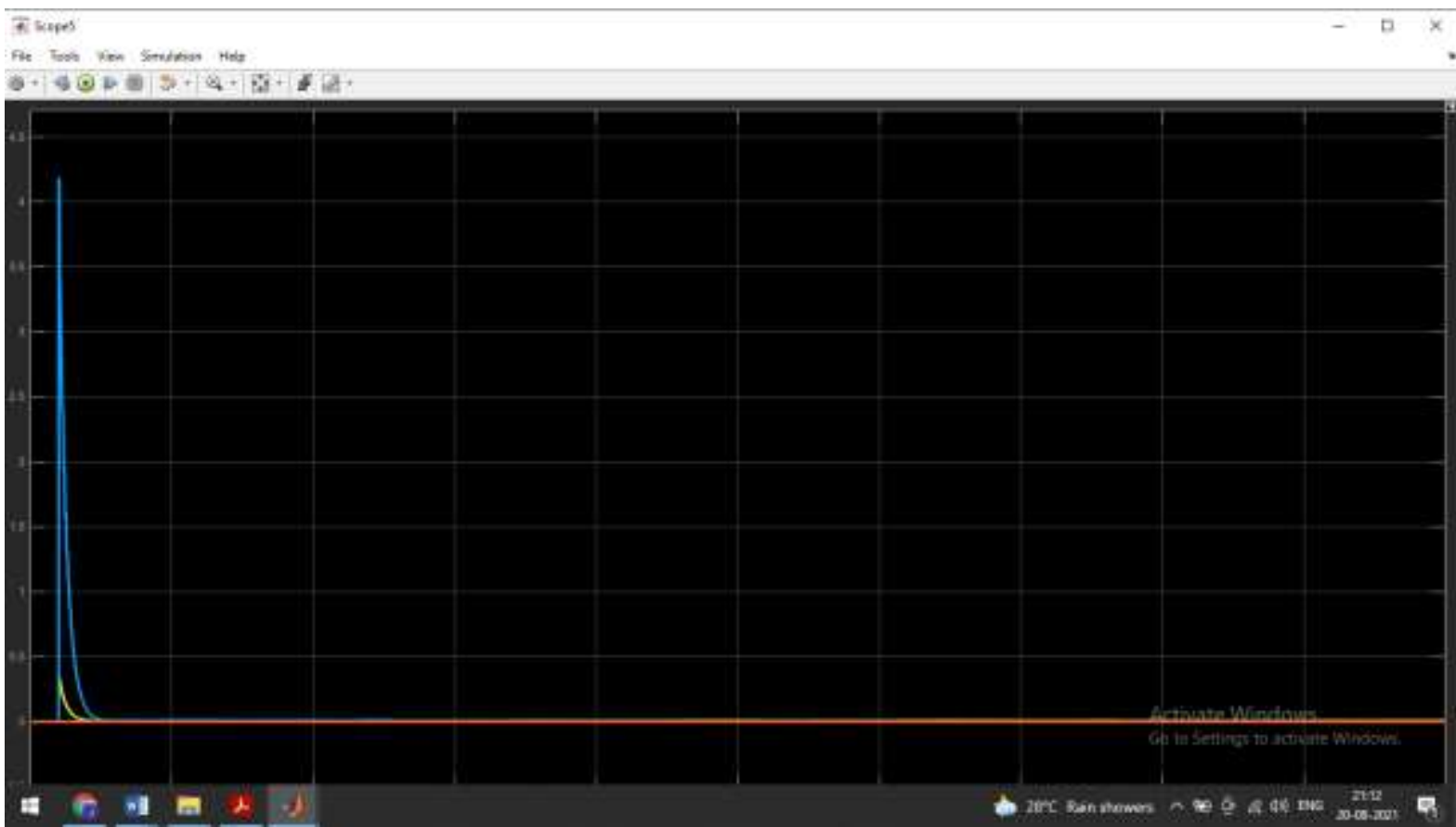




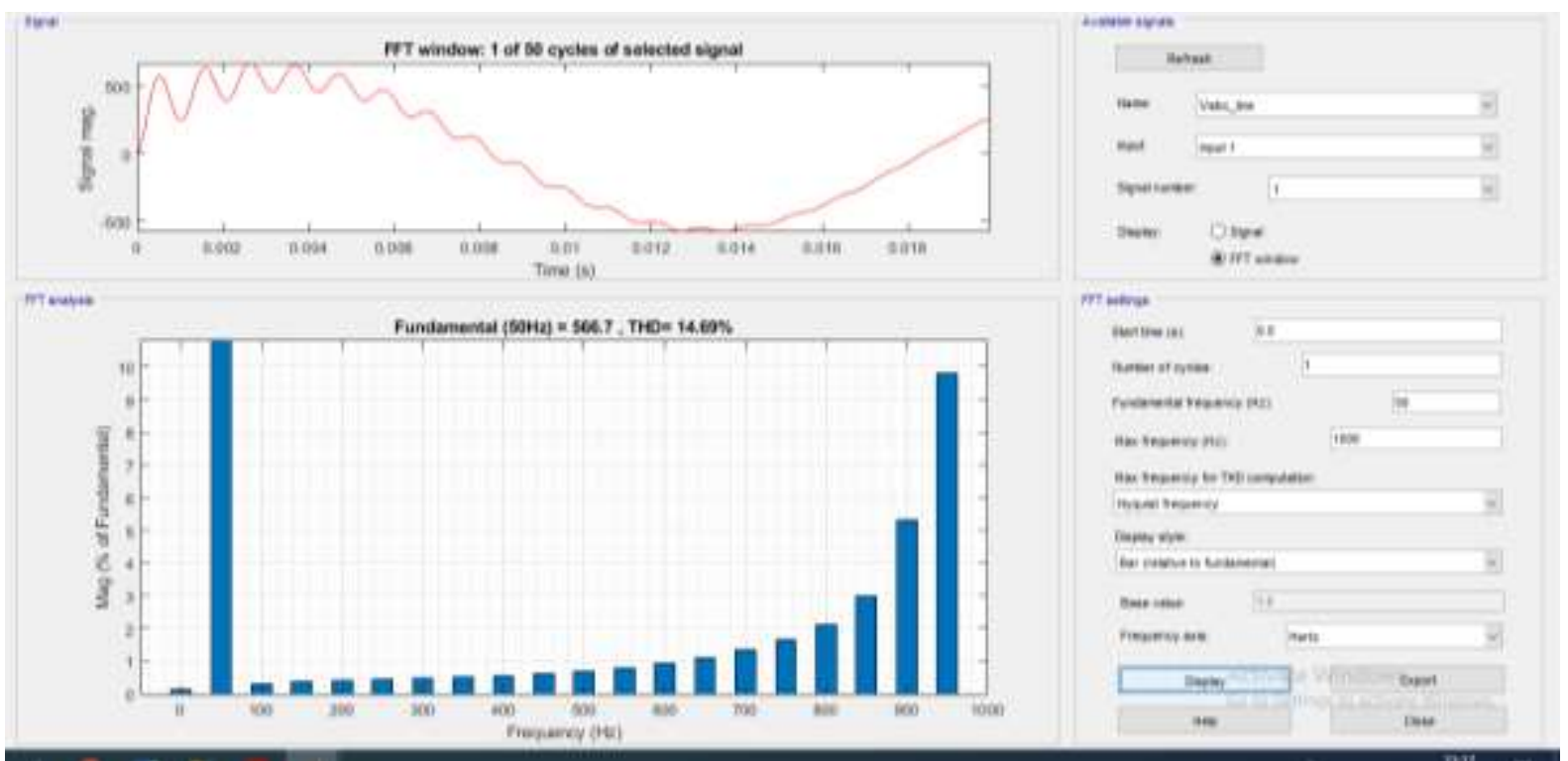

\section{Fig .7 Voltage THD}

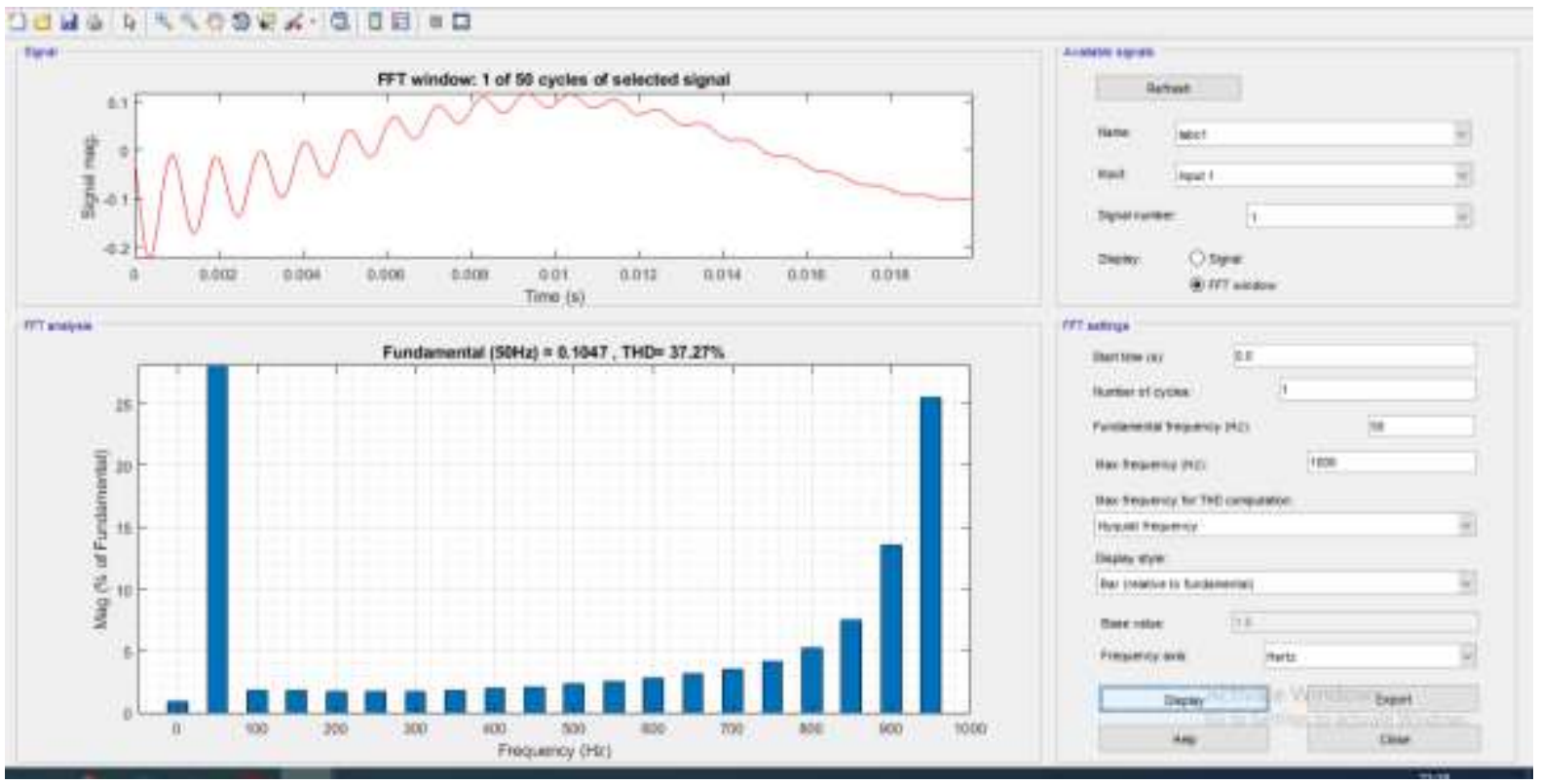

Fig .8 Current THD

\section{CONCLUSION}

After modelling of wind energy conversion system has been done, recorded and results shown in the figure above and the major aim is to maintain a dc link voltage to maintain constant and with the help of inverter control system it has also been almost accomplished. The designed pitch control system has he effects on harmonic distortion also e can see that Current THD is around $37 \%$ and voltage harmonics is around $14 \%$. As the voltage and current outputs have a smooth waveform we can work on harmonics in future with the help of FACTS devices like Statcom and SVC compensators to improve harmonic distortion as well as to reduce flickers and losses. After using filter of LC combination we can see that the output is smooth as well as in desired value to provide in the grid we can also work on filter configuration for the enhancement of output voltages and currents. 


\section{REFERENCES}

[1] [1]. H. Polinder, F. F. A. van der Pijl, G. -. de Vilder and P. J. Tavner, "Comparison of direct-drive and geared generator concepts for wind turbines," in IEEE Transactions on Energy Conversion, vol. 21, no. 3, pp. 725-733, Sept. 2006, doi: 10.1109/TEC.2006.875476.

[2] Dr. Abhishek Verma, Devendra Kumar, “"Modelling And Analysis Of Wind Energy System Connected With Grid And Total Harmonic Distortion Evaluation Based On Different Condition And Filter Configuration”," i manager journal, November - January 2021 issue (Volume No. 8, Issue No. 4) of i-manager's Journal on Power Systems Engineering (JPS).

[3] Juergen K Steinke IEEE Transactions on Energy Conversion, Vol. 14, No. 3, September 1999649 Use of an LC Filter to Achieve a Motor-friendly Performance of the PWM Voltage Source Inverter, Member, IEEE ABB Industries AG Department IU (Drive Products) CH-5300 Turgi, Switzerland

[4] Jay Verma, Yogesh Tiwari , IJRET International Journal of Recent Technology and Engineering (IJRTE) ISSN: 2277-3878, Volume-2 Issue-6, January 2014 Performance, Analysis and Simulation of Wind Energy Conversion System Connected with Grid.

[5] C. N. Bhende, S. Mishra, Senior Member, IEEE, and Siva Ganesh Malla - Permanent Magnet Synchronous Generator- Based Standalone Wind Energy Supply System -IEEE TRANSACTIONS ON SUSTAINABLE ENERGY, VOL. 2, NO. 4, OCTOBER 2011

[6] Staffan Jacobsson IMIT and Department of Industrial Dynamics, Chalmers University of Technology, Gothenburg, Sweden Anna Bergek IMIT and Department of Management and Economics, Linköping University, Linköping, Sweden — International wind energy development—World market update 1999,॥ BTM Consults Aps., Ringkobing, Denmark, 2000.

[7] M. Chinchilla, S. Arnaltes, and J. C. Burgos, "Control of permanent magnet generators applied to variable-speed wind-energy systems Connected to the grid," IEEE Trans. Energy Convers., vol. 21, no. 1, pp. 130-135, Mar. 2006.

[8] N. Mohan, T. M. Undeland, and W. P. Robbins, Power Electronics: Converters, Applications, and Design. Hoboken, NJ: Wiley, 2002.

[9] Dhirendra Deode1 Mr Nand Kishor Meena2 International Journal of Engineering and Innovative Technology (IJEIT) Volume 5, Issue 11, May 2016 A Review on "Performance Analysis of PMSG in Wind Energy Conversion System"

[10] Puneet K. Goel1, Bhim Singh2, Senior Member IEEE, S.S. Murthy3, Senior Member IEEE and Navin Kishore4, "Autonomous Hybrid System Using PMSGs for Hydro and Wind Power Generation" in IEEE 978-1-4244-46490, 2009.

[11] Manju Khare, Ganga Agnihotri Yogendra Kumar, \& V. K. Sethi, "Performance Analysis of a Grid connected Wind Energy system,"in American Journal of Engineering Research (AJER) e-ISSN : 2320-0847 p-ISSN : 23200936 Volume-03, Issue-02, pp-204-208,2014. 